\title{
Modeling \& Performance Scrutiny of Maximum Power Extraction Strategy in PMSG based Wind Energy Transformation System
}

\author{
Beena Kumari, Deepa Mehta
}

\begin{abstract}
Energy from wind is turning out to be a very promising alternative source technology in present and future power sector as it is environment-friendly and long-lasting with technological enhancements. Moreover, it occupies less space and has relative cost competitiveness. In the utility grid, the penetration of wind energy systems is expanding as the research progresses to capture greatest available wind power and operate the wind turbine (WT) with maximum possible aerodynamic efficiency. For this to accomplish a tracking controller is required to extract greatest wind power at all instants in the wide range of wind speeds. This paper presents a simple control technique for optimal power extraction from cut-in to rated wind speed range by sensing the dc-link power. It also embraces mathematical modeling of wind energy conversion system. The proposed algorithm shows excellent tracking capability under fluctuating wind conditions as revealed by power speed characteristic obtained in a wind energy system. The effectiveness of proposed strategy is verified by Matlab simulation.
\end{abstract}

Keywords: Wind aerodynamics, Maximum Power Point Tracking, Permanent Magnet Synchronous Generator

\section{INTRODUCTION}

$\mathrm{W}$ ind energy is one of the most favorable sources of sustainable energy due to its minimal environmental effect and abundant availability. Wind power technology has developed rapidly in recent years and so, it is considered as the most promising alternative source of energy. Wind power farms are accelerating at an exponential rate and is expected to devote $20 \%$ of global energy by 2030 [1]-[2]. However, due to the unpredictable and unstable nature of wind with highly stochastic and rapid time varying pattern, it confronts challenge for extracting maximum power at each and every instant of wind speed variations. So, an effective maximum power extraction strategy is called for satisfying the needs of optimal power capture and improved system aerodynamic efficiency. The various configuration of wind energy conversion system comprises of fixed speed or variable speed wind turbine (VSWT) driven directly or indirectly with synchronous or asynchronous generator [3]-[4]. Among these, variable speed wind turbine coupled with direct-driven

Manuscript received on September 01, 2020.

Revised Manuscript received on January 01, 2021.

Manuscript published on February 28, 2021.

* Correspondence Author

Beena Kumari*, Department of Electrical Engineering from Saurashtra University, Rajkot (Gujarat), India.

Dr. Deepa Mehta, Assistant Professor, G.D Goenka University, Gurugram (Haryana), India.

(C) The Authors. Published by Blue Eyes Intelligence Engineering and Sciences Publication (BEIESP). This is an open access article under the CC BY-NC-ND license (http://creativecommons.org/licenses/by-nc-nd/4.0/) permanent magnet synchronous generator (PMSG) is the most suited configuration. This is because VSWT furnish high energy conversion efficiency with improved power quality and reduced mechanical stresses. The system complexity and additional cost and losses due to power-electronic converters are the drawbacks of VSWT. These hurdles are counterbalanced by the usage of direct driven PMSG that incorporates gearbox exclusion, low speed-high torque output, eradication of ancillary excitation system or cooling system, low maintenance and operating cost, design flexibility and stable performance with power-electronic. converters/ inverters [5]. Hence, this configuration is becoming more popular for large scale and off-shore wind applications. With the rising exploration of wind energy systems in utility grid, it becomes necessary to efficiently capture maximum output power from wind turbine at all instants in wide range of wind speeds. This can be accomplished by incorporating a tracking strategy for power maximization that regulates rotor speed as per MPP for different wind speeds [6]-[10]. Enormous research and development work is carried with Traditional and advanced MPPT methodologies for achieving excellent tracking under wind speed variations. Among the various techniques discussed so far in literature includes measurement of wind speed by anemometer as in Tip-speed ratio (TSR) or store optimal speed-power values for different speeds in look-up table as in Optimal Torque Control (OTC) and Power Signal Feedback (PSF). These techniques were based on measurement of mechanical parameters like wind speed or wind turbine parameters [11-[14]. Such strategies revealed negative performance due to aging and environmental impact which made research towards advanced techniques. Advanced techniques [15]-[18] get differentiated from traditional techniques by measurement of electrical parameters like voltage, current or power that are both easy, accurate and cost-effective to measure. Moreover, they do not need mathematical modeling of the physical system and are not affected by system parameter variations. The need of mechanical sensors is also not required for them. The various MPPT techniques included in this category are Hill Climb Search (HCS), Incremental Conductance (INC), Optimum Relation Based (ORB), Soft computing techniques such as Fuzzy logic control (FLC), Artificial Neural Network (ANN), Adaptive Neuro Fuzzy Inference System (ANFIS) and Metaheuristic optimization techniques such as Democratic Joint Operations Algorithm (DJOA), Particle Swarm Optimisation (PSO), Whale Optimisation Algorithm (WOA), Grey Wolf Optimisation (GWO). 


\section{Modeling \& Performance Scrutiny of Maximum Power Extraction Strategy in PMSG based Wind Energy Transformation System}

This paper proposes a maximum power extraction strategy based on Hill Climb Search and Optimal Torque strategy for PMSG based WECS by controlling the dc link power output at the rectifier terminals.

It makes use of single IGBT based active semiconductor switch to regulate generator torque for maximum power extraction.

It is a cheap and less complex technique for wind energy systems. This research paper is presented as follows. Section II includes the modeling of wind energy conversion system, Section III presents the concept of MPPT with power speed characteristic plot, Section IV gives the representation and analysis of maximum power extraction strategy with matlab Simulink model and section V concludes the article.

\section{MODELING OF WECS}

Wind aerodynamic system incorporates a wind turbine linked to electrical generator through the shaft of turbine. The electrical output is regulated and controlled by power-electronic interface including rectifier, boost converter, inverter and then integrated with utility grid [19]-[20].

\section{A. Wind turbine model}

Wind turbines convert the available wind power into mechanical power (Pm) as given by eq. (1)

$P_{\mathrm{m}}=0.5 \rho C_{p}\left(\lambda_{s} \beta\right) A v^{3}$

$C_{p}\left(\lambda_{v} \beta\right)=0.73\left(\frac{151}{\lambda_{\mathrm{f}}}-0.58 \beta-0.002 \beta^{2.14}-13.2\right) e^{\frac{-124}{\lambda_{\mathrm{f}}}}$

$\frac{1}{\lambda_{i}}=\frac{1}{\lambda+0.02 \beta}-\frac{0.03}{1+\beta^{3}}$

$\lambda=\frac{R \omega_{m}}{\lambda}$

$\lambda=\frac{v_{\text {max }}}{P_{2}} \rho A\left(\frac{\omega_{m \mathrm{~m}} R}{\lambda_{\text {opt }}}\right)^{\mathrm{a}} C_{\text {popt }}$

Where $C_{p}$ is power coefficient which is a function of pitch angle $\beta$ and TSR $\lambda, \mathrm{R}$ is the blade radius in meters and $\mathrm{A}$ is the blade swept area in $\mathrm{m}^{2}, v$ is the wind velocity in $\mathrm{m} / \mathrm{s}, \rho$ is the air density in $\mathrm{Kg} / \mathrm{m}^{3}, \omega_{\mathrm{m}}$ is the rotor speed in $\mathrm{rad} / \mathrm{s}$. The optimum parameters for maximum power $P_{\max }$ are $\lambda_{\text {opt }}$ and $C_{\text {popt }}$. Ceaseless working of wind turbine guarantees to achieve optimal power at any wind speed as explained by non-linear power-speed characteristic of wind turbine in section III.

\section{B. PMSG model}

PMSG transforms mechanical energy obtained from wind turbine into electrical energy. The model of Permanent Magnet Synchronous Machine (PMSM) is established in d-q reference frame [18]-[19] with the voltage and torque equations expressed as

$\left(\begin{array}{l}v_{s d} \\ v_{s q}\end{array}\right)=-R_{s}\left(\begin{array}{l}i_{s d} \\ i_{s q}\end{array}\right)-\frac{d}{d t}\left(\begin{array}{c}L_{d} i_{s d} \\ L_{q q} i_{s q}\end{array}\right)+\omega_{v}\left(\begin{array}{c}-L_{q q} i_{s q} \\ L_{d} i_{s d}+\psi_{f}\end{array}\right)$

$T e=p\left[\left(L_{d}-L_{q}\right) i_{s d} i_{s q}+i_{s q} \Psi_{f}\right]$

where $v_{s d}, v_{s q}, i_{s d}, i_{s q}$ are the generator terminal d-q voltages and d-q currents, $L_{d d}$ and $L_{q q}$ are the d-q inductances, $R_{g}$ is the resistance, $\psi_{f}$ is the permanent magnet flux that links the stator windings and $T e$ is the electromagnetic torque in $\mathrm{Nm}$.

The dynamics of shaft system for direct-drive train of PMSG variable speed wind turbine is modeled as:

$j \frac{d \omega_{m}}{d d_{t}}+D \omega_{m}=T_{m}-T_{e}$

Where $j$ is the generator inertia, D is the coefficient of rotor damping, $T_{m}$ is the mechanical torque developed by wind turbine, $\omega_{m}$ and $\omega_{e}$ are the mechanical and electrical speeds related by number of poles, $\mathrm{P}$ as

$\omega_{e}=\frac{p}{2} \omega_{m}$

\section{Diode Bridge Rectifier}

The function of diode bridge rectifier at the output terminals of PMSG is to convert three phase AC voltage into DC voltage. The average output voltage of the rectifier is given by

$$
V_{\text {avg }}=\frac{a \sqrt{a} V_{p h}}{\pi}
$$

Where Vph is the peak value of the phase voltage of the PMSG.

\section{Boost Converter}

The rectified DC voltage is converted into DC of desired magnitude with the help of boost converter that consists of inductor, IGBT switch, diode and capacitor as shown in Fig.1. It works in continuous conduction mode with the design expressions as given:

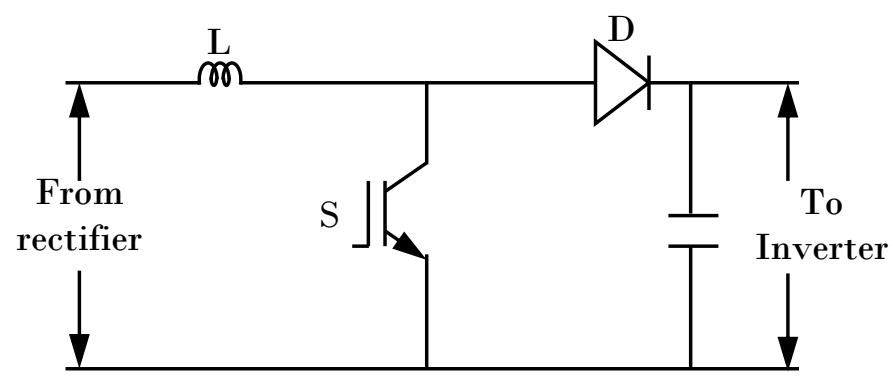

Fig. 1.Boost Converter Circuit [20]

The average output voltage of converter $\left(\mathrm{V}_{\mathrm{DC}}\right)$ is

$V_{D C}=\frac{V_{a v g}}{(1-k)}$

$L=\frac{k V_{\text {ouvg }}}{f_{s} \Delta N}$

$C=\frac{k I}{f_{s} \Delta v_{c}}$

Where $\Delta I$ the peak to peak ripple is current of inductor, $\Delta V_{c}$ is the peak to peak ripple voltage of capacitor, $k$ is the duty ratio of the switch $\mathrm{S}$ and $f_{s}$ is the switching frequency.

\section{MAXIMUM POWER POINT TRACKING}

Wind energy conversion system employ maximum power extraction strategy for sustainable power output. The power output from wind turbine has four operating zones when plotted with wind velocity as shown in fig. 2 . The power obtained in zones 1 and 4 is not reliable as the wind is too low in first zone and too high in last zone that can cause damage the wind turbine. Zone 2 is the optimal zone for maximum power extraction in wind energy systems. The power output is

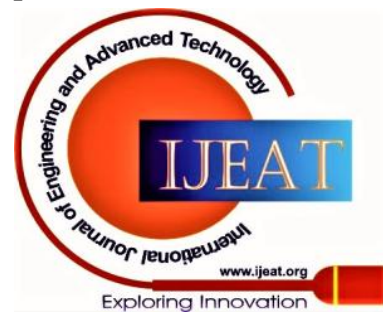

(C) Copyright: All rights reserved. 
limited in zone 3 by pitch angle control for safety of turbine.

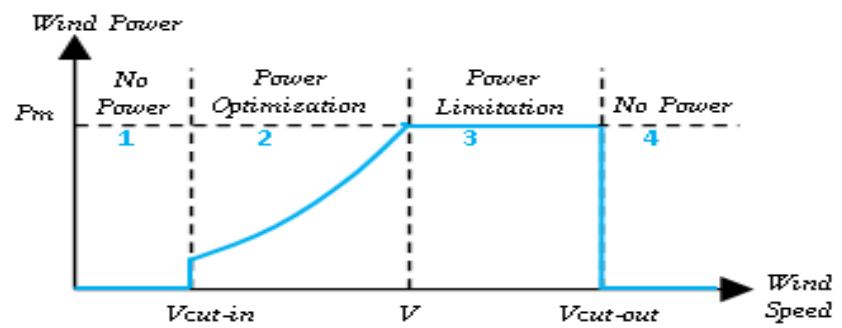

Fig. 2.Operating Zones of Wind Turbine Power-Speed Curve [8]

The aim of maximum power point tracking controller is to trace the curve obtained by connecting maximum power points at different wind speeds. This is achieved by regulating rotor speed to optimal speed under wind speed variations [21]-[23]. The expression for optimum rotor speed is given by $\omega_{m_{-} \text {opt }}=\frac{\lambda_{\text {opt }}{ }^{D}}{R}$

This results in maximum power expression as:

$P_{m_{-} \text {opt }}=0.5_{\rho} A C_{P_{o p t}}\left(\frac{\omega_{m_{\text {optR }}}}{\lambda_{\text {opt }}}\right)^{a}=K_{\text {opt }}\left(\omega_{m_{-} \text {opt }}\right)^{a}$

Where

$K_{\text {opt }}=0.5_{\rho} A C_{\rho_{-} \text {opt }}\left(\frac{R}{\lambda_{\text {opt }}}\right)^{a}$

And maximum torque as:

$T_{m_{-} \text {opt }}=K_{\text {opt }}\left(\omega_{m_{-} \text {opt }}\right)^{2}$

With these expressions, power speed curve is plotted for different speeds and optimal active power curve is achieved [24]-[27]. The concept of maximum power point tracking is explained by finding out power at different rotor speeds (varied from $25 \mathrm{rpm}$ to $500 \mathrm{rpm}$ ) for a particular wind speed. It is observed that maximum power at any wind speed is obtained at a particular rotor speed. Table I shows the maximum power output of $1101 \mathrm{~W}$ at $125 \mathrm{rpm}$ rotor speed when the wind speed was taken as $6 \mathrm{~m} / \mathrm{s}$. In the same way, maximum power at specific rotor speed is determined in Table II and Table III at wind speeds of $12 \mathrm{~m} / \mathrm{s}$ and $14 \mathrm{~m} / \mathrm{s}$. Pitch angle is changed in Table III to keep the wind turbine working at rated speed (275 rpm) and rated power (8500 W) for given study All other outputs are summarized in Table IV.

Table- I: Power Output for rotor speed variation (25 rpm to 500rpm) for wind speed at $6 \mathrm{~m} / \mathrm{s}$

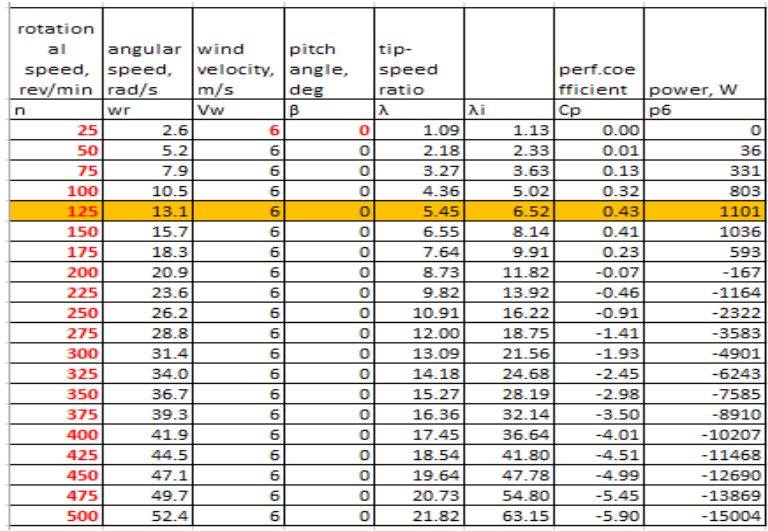

Table- II: Power Output for rotor speed variation (25 rpm to 500rpm) for wind speed at $12 \mathrm{~m} / \mathrm{s}$

\begin{tabular}{|c|c|c|c|c|c|c|c|}
\hline $\begin{array}{c}\text { rotation } \\
\text { al } \\
\text { speed, } \\
\text { rev } / \mathrm{min}\end{array}$ & $\begin{array}{l}\text { angular } \\
\text { speed, } \\
\mathrm{rad} / \mathrm{s}\end{array}$ & \begin{tabular}{|l} 
wind \\
velocity, \\
$\mathrm{m} / \mathrm{s}$
\end{tabular} & \begin{tabular}{|l} 
pitch \\
angle, \\
deg
\end{tabular} & $\begin{array}{l}\text { tip- } \\
\text { speed } \\
\text { ratio }\end{array}$ & & $\begin{array}{l}\text { perf.coe } \\
\text { fficient }\end{array}$ & power, W \\
\hline n & wrr & $V w$ & $\beta$ & $\lambda$ & $\lambda \mathrm{i}$ & $C p$ & $\mathrm{p} 12$ \\
\hline 25 & 2.6 & 12 & 0 & 0.55 & 0.55 & 0.00 & 0 \\
\hline 50 & 5.2 & 12 & 0 & 1.09 & 1.13 & 0.00 & 0 \\
\hline 75 & 7.9 & 12 & 0 & 1.64 & 1.72 & 0.00 & 25 \\
\hline 100 & 10.5 & 12 & 0 & 2.18 & 2.33 & 0.01 & 289 \\
\hline 125 & 13.1 & 12 & 0 & 2.73 & 2.97 & 0.06 & 1141 \\
\hline 150 & 15.7 & 12 & 0 & 3.27 & 3.63 & 0.13 & 2651 \\
\hline 175 & 18.3 & 12 & 0 & 3.82 & 4.31 & 0.22 & 4546 \\
\hline 200 & 20.9 & 12 & 0 & 4.36 & 5.02 & 0.32 & 6423 \\
\hline 225 & 23.6 & 12 & 0 & 4.91 & 5.76 & 0.39 & 7923 \\
\hline 250 & 26.2 & 12 & 0 & 5.45 & 6.52 & 0.43 & 8805 \\
\hline 275 & 28.8 & 12 & $\underline{0}$ & 6.00 & 7.32 & 0.44 & 8940 \\
\hline 300 & 31.4 & 12 & 0 & 6.55 & 8.14 & 0.41 & 8288 \\
\hline 325 & 34.0 & 12 & 0 & 7.09 & 9.01 & 0.34 & 6870 \\
\hline 350 & 36.7 & 12 & 0 & 7.64 & 9.91 & 0.23 & 4741 \\
\hline 375 & 39.3 & 12 & 0 & 8.18 & 10.84 & 0.10 & 1978 \\
\hline 400 & 41.9 & 12 & 0 & 8.73 & 11.82 & -0.07 & -1339 \\
\hline 425 & 44.5 & 12 & 0 & 9.27 & 12.85 & -0.25 & -5127 \\
\hline 450 & 47.1 & 12 & 0 & 9.82 & 13.92 & -0.46 & -9309 \\
\hline 475 & 49.7 & 12 & 0 & 10.36 & 15.04 & -0.68 & -13813 \\
\hline 500 & 52.4 & 12 & 0 & 10.91 & 16.22 & -0.91 & -18576 \\
\hline
\end{tabular}

Table- III: Power Output for rotor speed variation (25 rpm to 500rpm) for wind speed at $14 \mathrm{~m} / \mathrm{s}$

\begin{tabular}{|c|c|c|c|c|c|c|c|}
\hline$r=$ & 25 & blade rac & dius. $m$ & & & & \\
\hline$\rho o=$ & 1.2 & air densi & $\mathrm{ty}, \mathrm{kg} / \mathrm{m} 3$ & & & & \\
\hline $\begin{array}{c}\text { rotation } \\
\text { al } \\
\text { speed, } \\
\mathrm{rev} / \mathrm{min}\end{array}$ & $\begin{array}{l}\text { angular } \\
\text { speed, } \\
\mathrm{rad} / \mathrm{s}\end{array}$ & $\begin{array}{l}\text { wind } \\
\text { velocity, } \\
\mathrm{m} / \mathrm{s}\end{array}$ & $\begin{array}{l}\text { pitch } \\
\text { angle, } \\
\text { deg }\end{array}$ & $\begin{array}{l}\text { tip- } \\
\text { speed } \\
\text { ratio }\end{array}$ & & $\begin{array}{l}\text { perf.coe } \\
\text { fficient }\end{array}$ & power, W \\
\hline $\mathrm{n}$ & wr & Vw & $\beta$ & $\lambda$ & $\lambda i$ & $C p$ & \\
\hline 25 & 2.6 & 14 & 5.3 & 0.47 & 0.57 & 0.00 & 의 \\
\hline 50 & 5.2 & 14 & 5.3 & 0.94 & 1.04 & 0.00 & 0 \\
\hline 75 & 7.9 & 14 & 5.3 & 1.40 & 1.51 & 0.00 & 10 \\
\hline 100 & 10.5 & 14 & 5.3 & 1.87 & 1.98 & 0.00 & 127 \\
\hline 125 & 13.1 & 14 & 5.3 & 2.34 & 2.44 & 0.02 & 569 \\
\hline 150 & 15.7 & 14 & 5.3 & 2.81 & 2.91 & 0.05 & 1485 \\
\hline 175 & 18.3 & 14 & 5.3 & 3.27 & 3.38 & 0.09 & 2828 \\
\hline 200 & 20.9 & 14 & 5.3 & 3.74 & 3.85 & 0.14 & 4406 \\
\hline 225 & 23.6 & 14 & 5.3 & 4.21 & 4.32 & 0.19 & 5985 \\
\hline 250 & 26.2 & 14 & 5.3 & 4.68 & 4.79 & 0.23 & 7355 \\
\hline 275 & 28.8 & 14 & 5.3 & 5.14 & 5.25 & 0.26 & 8361 \\
\hline 300 & 31.4 & 14 & 5.3 & 5.61 & 5.72 & 0.28 & 8908 \\
\hline 325 & 34.0 & 14 & 5.3 & 6.08 & 6.19 & 0.28 & 8949 \\
\hline 350 & 36.7 & 14 & 5.3 & 6.55 & 6.66 & 0.26 & 8474 \\
\hline 375 & 39.3 & 14 & 5.3 & 7.01 & 7.13 & 0.23 & 7499 \\
\hline 400 & 41.9 & 14 & 5.3 & 7.48 & 7.60 & 0.19 & 6055 \\
\hline 425 & 44.5 & 14 & 5.3 & 7.95 & 8.07 & 0.13 & 4185 \\
\hline 450 & 47.1 & 14 & 5.3 & 8.42 & 8.54 & 0.06 & 1932 \\
\hline 475 & 49.7 & 14 & 5.3 & 8.88 & 9.00 & -0.02 & -658 \\
\hline 500 & 52.4 & 14 & 5.3 & 9.35 & 9.47 & -0.11 & -3538 \\
\hline
\end{tabular}

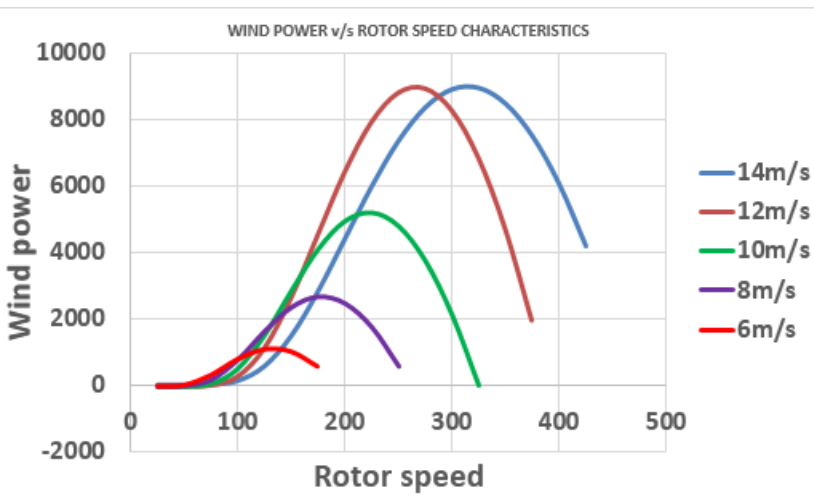

Fig. 3.Power-speed curve

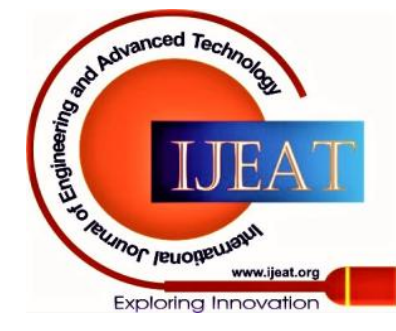


Modeling \& Performance Scrutiny of Maximum Power Extraction Strategy in PMSG based Wind Energy Transformation System

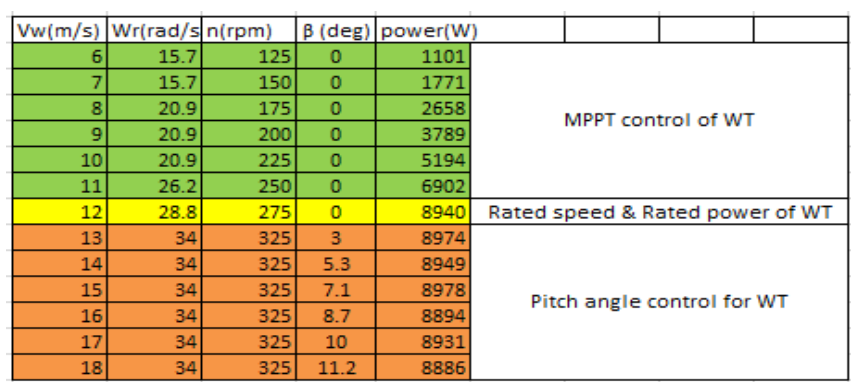

Table- IV: Summary of Power Output at different wind speeds

\section{SIMULINK MODEL AND ANALYSIS}

The model of PMSG based wind energy conversion system is prepared using Simpowersytem Toolbox of Matlab Simulink software as shown in Fig.4. The maximum power extraction strategy is represented in Fig.5. The wind turbine and PMSG parameters are shown in Table V. The sampling time used for simulation is $50 \mu$ s. Fig.6 shows the step variations of wind speed at different instants. It is observed from the power-speed characteristic obtained in Fig.7 that the maximum power extraction strategy efficiently tracks the maximum power with wind speed variations. So, the proposed strategy can be used to extract maximum power from variable speed wind turbine under fluctuating wind conditions.

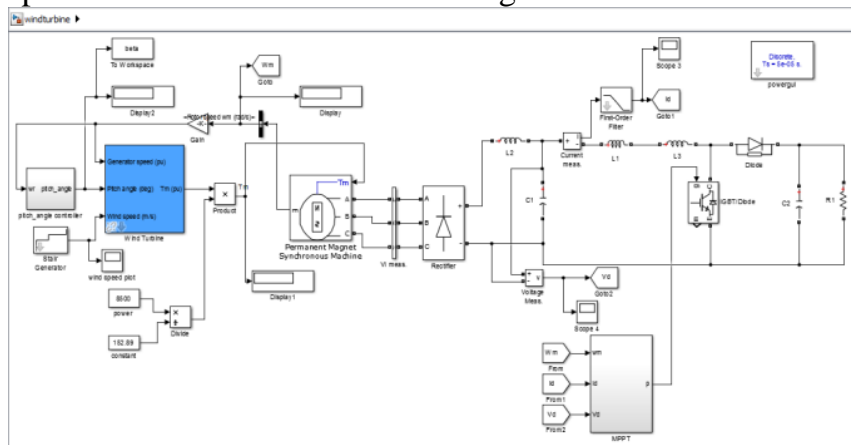

Fig. 4.WECS Simulink model

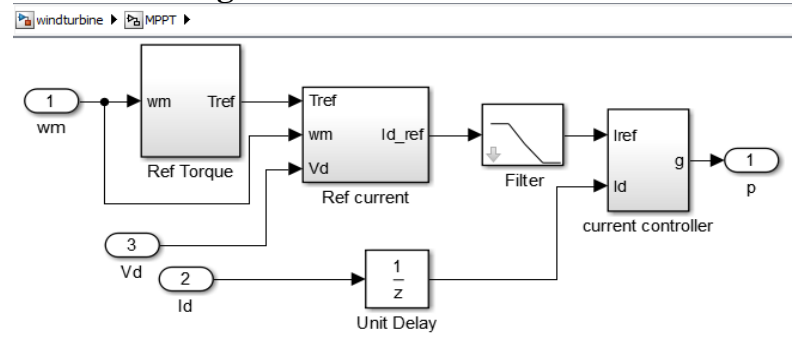

Fig. 5.MPPT model

Table- V: Wind Turbine and PMSG values

\begin{tabular}{|c|c|}
\hline Parameters & Values \\
\hline \multicolumn{2}{|c|}{ Wind Turbine Parameters } \\
\hline Base wind speed & $12 \mathrm{~m} / \mathrm{s}$ \\
\hline Wind Turbine & $8.5 \mathrm{KW}$ \\
\hline Load Power & $10 \mathrm{Kw}$ \\
\hline \multicolumn{2}{|c|}{ PMSG Parameters } \\
\hline Stator resistance (Rs) & $0.425 \mathrm{ohms}$ \\
\hline Inductance ( $\mathrm{Ld}, \mathrm{Lq})$ & $0.0082 \mathrm{H}$ \\
\hline Flux linkage & $0.433 \mathrm{~V} . \mathrm{s}$ \\
\hline Voltage constant & $392.684 \mathrm{v}$ peak $\mathrm{L}-\mathrm{I}$ \\
\hline Torque Constant & $3.2475 \mathrm{~N}-\mathrm{m}$ \\
\hline Inertia Constant & $0.01197 \mathrm{~kg} \cdot \mathrm{m} \wedge 2$ \\
\hline Friction factor & 0.001189 N.m.s \\
\hline Poles & 5 \\
\hline \multicolumn{2}{|c|}{ Filter Parameters } \\
\hline $\mathrm{R}$ & $10 h m$ \\
\hline $\mathrm{L}$ & $0.1 \mathrm{mH}$ \\
\hline $\mathrm{C}$ & $100 \mu F$ \\
\hline
\end{tabular}

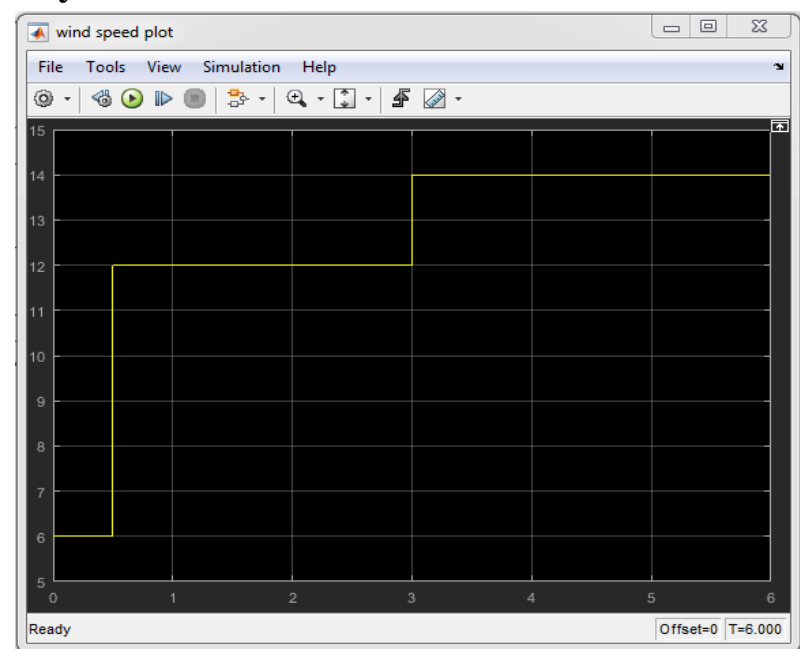

Fig. 6.Wind speed input plot

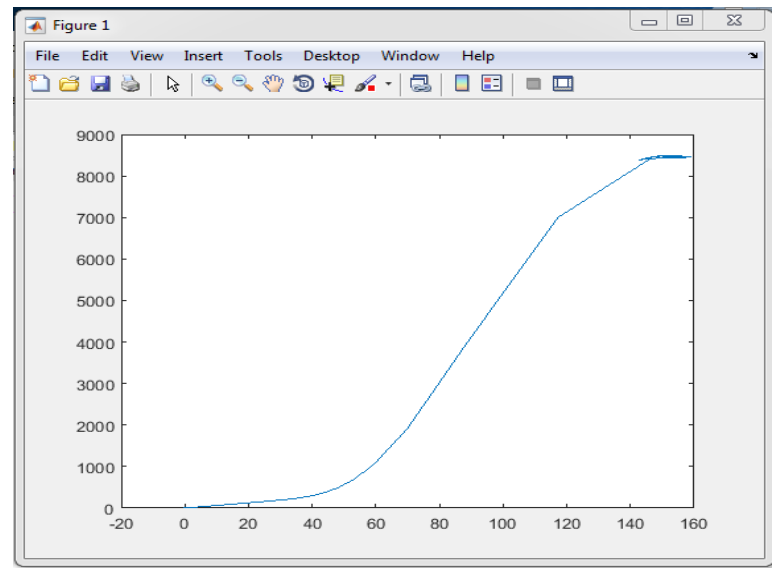

Fig. 7.Optimal Power-Speed Curve showing maximum power tracking

\section{V.CONCLUSION}

A maximum power extraction strategy for PMSG based wind energy conversion system is presented and simulated for variable wind speed profile. The proposed strategy have achieved the objective of extracting maximum power from any wind speed without prior knowledge of wind speed or rotor speed. Wind turbine aerodynamic attributes are also not required for this strategy to progress.

The system behaves efficiently under rapid variations of wind conditions as revealed by the power-speed characteristic obtained in Matlab Simulink model. Future application may include innovation of some system technology to generate more power at low wind speeds, use of multi-phase PMSG for effective fault tolerant capability and proper grid connection of PMSG based WECS.

\section{REFERENCES}

1. M.M Hossain and M.H Ali, "Future research directions for wind turbine generator systems," Renewable Energy Sustainable Review, vol.49, pp.481-489, 2015.

2. J.K Kaldellis and D. Apostolou, "Life cycle energy and carbon footprint of offshore wind energy. Comparison with onshore counterpart," Renewable Energy, vol.108, pp.72-84, Aug 2017.

Published By:

Blue Eyes Intelligence Engineering and Sciences Publication

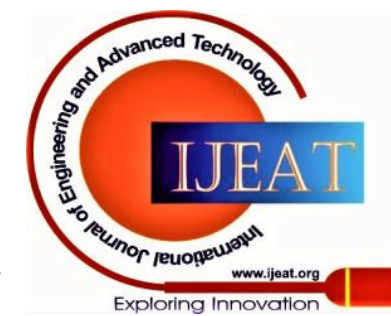
(C) Copyright: All rights reserved. 
3. A. Jain, S. Shankar and V. Vanitha, "Power Generation Using Permanent Magnet Synchronous Generator (PMSG) Based Variable Speed Wind Energy Conversion System (WECS): An Overview," Journal of Green Engineering, vol.7, no.4, pp.477-504, Oct 2017.

4. S.Chatterjee and S.Chatterjee, "Review on the techno-commercial aspects of wind energy conversion system," IET Renewable Power Generation, vol.12, no.14, pp.1581-1608, Jul 2018.

5. M.E Haque, M. Negnevitsky and K.M Muttaqi, "A novel control strategy for a variable-speed wind turbine with a permanent-magnet synchronous generator," IEEE transactions on industry applications, vol.46, no.1, pp.331-339, Nov 2009.

6. M.A Abdullah, A.H Yatim and C.W Tan, "Maximum power point tracking algorithms for wind energy system: a review," International Journal of Renewable Energy Resources, vol.2, no.1, pp.33-39, Oct 2017.

7. S.M Kazmi, H. Goto, H.J Guo and O. Ichinokura, "Review and critical analysis of the research papers published till date on maximum power point tracking in wind energy conversion system," IEEE Energy Conversion Congress and Exposition, pp.4075-4082, sept 2010.

8. D.Kumar and K.Chatterjee, "A review of conventional and advanced MPPT algorithms for wind energy systems," Renewable and sustainable energy reviews, vol.55, pp.957-970, Mar 2016.

9. S.M Kazmi, H. Goto, H.J Guo and O. Ichinokura, "Review and critical analysis of the research papers published till date on maximum power point tracking in wind energy conversion system," IEEE Energy Conversion Congress and Exposition, pp.4075-4082, sept 2010.

10. K. Karthi, R. Radhakrishnan, J.M Baskaran and L.S Titus, "A Review of Maximum Power Point Tracking Controls and Wind Electric Generators," International Conference on Inventive Research in Computing Applications (ICIRCA), pp.1122-1126, Jul 2018.

11. M. Nasiri, J. Milimonfared and S.H Fathi, "Modeling, analysis and comparison of TSR and OTC methods for MPPT and power smoothing in permanent magnet synchronous generator-based wind turbines," Energy Conversion and Management, vol.86, pp.892-900, Oct 2014.

12. E.K Yaylac1, "Improving Efficiency of the Tip Speed Ratio-MPPT Method for Wind Energy Systems by Using an Integral Sliding Mode Voltage Regulator," Journal of Energy Resources Technology, vol.140, no.5, pp.051203-1-6, May 2018.

13. S.S Kumar, K. Jayanthi and N.S Kumar, "Maximum power point tracking for a PMSG based variable speed wind energy conversion system using optimal torque control," International Conference on Advanced Communication Control and Computing Technologies (ICACCCT), pp.347-352, May 2016

14. Z.R Labidi, H. Schulte and A. Mami, "Modeling and optimal torque control of small wind turbines with permanent magnet synchronous generators," IEEE International Conference on Green Energy Conversion Systems (GECS), pp.1-6, Mar 2017.

15. R. Tiwari and N.R Babu, "Fuzzy logic based MPPT for permanent magnet synchronous generator in wind energy conversion system," IFAC-Papers On Line, vol.49, no.1, pp.462-467, Jan 2016.

16. R. Tiwari, K. Krishnamurthy, R. Neelakandan, S. Padmanaban and P. Wheeler, "Neural network based maximum power point tracking control with quadratic boost converter for PMSG - wind energy conversion system," Electronics, vol.7, no.2, Feb 2018.

17. Y. Soufi, S. Kahla and M. Bechouat, "Feedback linearization control based particle swarm optimization for maximum power point tracking of wind turbine equipped by PMSG connected to the grid," International journal of hydrogen energy, vol.41, no..45, pp.20950-20955, Dec 2016

18. H.H Mousa, A.R Youssef, E.E Mohamed, "Variable step size P\&O MPPT algorithm for optimal power extraction of multi-phase PMSG based wind generation system," International Journal of Electrical Power \& Energy Systems, vol.108, pp.218-231,Jun 2019.

19. O. P. Mahela and A. G. Shaik, "Comprehensive overview of grid interfaced wind energy generation systems," Renewable and Sustainable Energy Reviews, vol.57, pp.260-281, May 2016.

20. T. Porselvi and R. Muthu, "Wind Energy Conversion System with Boost Converter and CHB MLI with Single DC Input," International Journal of Engineering and Technology, vol.6, no.1, pp.138-145, Feb- Mar 2014.

21. M. Kesraoui, N. Korichi and A. Belkadi, "Maximum power point tracker of wind energy conversion system," Renewable energy, vol.36, pp.2655-2662, Oct 2011.

22. M.E Haque, M.Negnevitsky and K.M Muttaqi,'A novel control strategy for a variable-speed wind turbine with a permanent-magnet synchronous generator," IEEE transactions on industry applications,Vol.46,no.1, pp.331-339, Jan 2010.

23. Y. Xia, K.H Ahmed and B.W Williams, "A new maximum power poin tracking technique for permanent magnet synchronous generator based
24. C.H Tran, F. Nollet, N.Essounbouli and A. Hamzaoui, "Maximum power point tracking techniques for wind energy systems using three levels boost converter," IOP Conference Series: Earth and Environmental Science, vol.154, no.1, May 2018.

25. A.Saidi and B.Chellali,'Simulation and control of solar wind hybrid renewable power system." IEEE International Conference on systems and control, pp.51-56, May 2017.

. J. Hussain and A.K Mishra, "Adaptive maximum power point tracking Transactions on Energy Conversion, vol. 31, no.2, pp.no 697-705, Jun 2016.

. Yaramasu, A. Dekka, M.J. Durán, S. Kouro and B. Wu, converters and controls," IET Electric Power Applications, vol.11, no.6, pp.956-968, Jul 2017.

\section{Authors ProfiLe}

Beena Kumari received the B.E degree in electrical engineering from Saurashtra University, Rajkot, Gujara in 2003 and MTech in Power Electronics, Electrical Machines and Drives from MDU, Rohtak, Haryana in 2010. She is now a Research Scholar at G.D Goenka University, Gurugram, Haryana since 2017. She has about eight years of teaching experience at an engineering college and two years of design experience at a transformer industry. Her research interest includes non-conventional energy systems, MPPT techniques of wind energy conversion system, computer-aided design of electric machines, power-electronics interface devices, control of electric machines, permanent-magnet machines and magnetic devices. She has published two papers at international conference that are based on maximum power point tracking of permanent magnet synchronous generator-based wind energy conversion system. Out of these, one research paper is also available at ieee explore. Her research intends to progress towards making wind energy system to work over the full range of operational wind profiles and intelligent technique for blade pitch control. Her research will try to develop an advanced intelligent controlled optimized grid-connected permanent magnet synchronous generator-based wind energy conversion

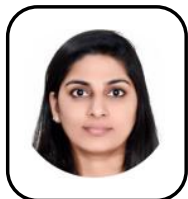

Dr. Deepa Mehta is an expert in the area of compute networks and machine learning and has taught subjects in this area for more than eight years in reputed colleges and universities. She has authored more than 20 research papers in reputed journals and international conferences. She has organized several successful workshops and Winter Schools in innovative and neoteric areas. She is also a certified trainer of Python from Coursera. She is currently working as Assistant Professor at G.D Goenka University, Gurugram, Haryana in School of Manav Rachna International Institute of Research and Study; M.Tech and Communication Engineering) from Maharshi Dayanand University; and B.Tech (Electronics and Communication Engineering) from Maharshi Dayanand University. Her current research interests are on sustainable energy using the optimal artificial intelligence and machine learning techniques. She maintains an upward learning curve by adapting to ainable environment goal.

Contribution to Profession and Awards (from 2015) includes work as a Reviewer, Editorial Review Board, European Alliance for Innovation (Publisher - European Alliance for Innovation) and Session Chair, Second International Conference on ICT for Digital, Smart and Sustainable Development, Jamia Hamdard University, New Delhi, 2020.

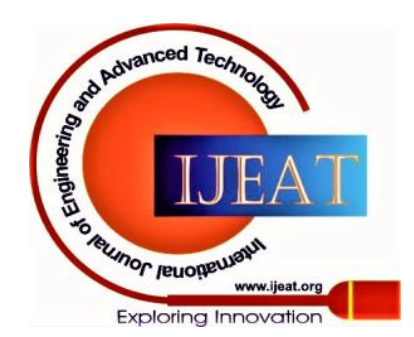

